\title{
Creating a Surgical Controversy
}

\section{From Kentucky to Edinburgh to the Pages of the Lancet: Ovarian Surgery in the Early Nineteenth Century}

John Bell would never receive the report Ephraim McDowell sent to him about his successes with ovarian surgery in Kentucky. In May 1817, Bell left for Italy where he would remain until his death in 1820. The report instead fell into the hands of the surgeon John Lizars, who had been Bell's partner in practice. Lizars, a respected instructor in anatomy and surgery at the Edinburgh extra-mural school, had his curiosity aroused by McDowell's new operation, and the challenge of removing diseased ovaries was to become a project for him over the next several years. In 1825, he published a monograph, Observations on Extraction of Diseased Ovaria, in which he detailed four cases where he had attempted the procedure. Lizars' results were mixed; of his four patients, one died from peritoneal inflammation, another was discovered to have been misdiagnosed, with no tumour to be found upon opening the abdomen, and in a third, the operation had to be abandoned because of extensive adhesions. Only one case brought success, a large diseased ovary was removed from a patient who-after a tense three-month period where she suffered severe post-operative illness-had survived. But even this achievement was tempered by Lizars' revelation that the patient's other ovary had also been diseased, but which he had been unable to remove. ${ }^{1}$

S. Frampton, Belly-Rippers, Surgical Innovation and the Ovariotomy

Controversy, Medicine and Biomedical Sciences in Modern History, https://doi.org/10.1007/978-3-319-78934-7_3 
Lizars' work received mixed reviews from the medical press. The Medico-Chirurgical Review, one of the more established London medical journals, edited by the surgeon James Johnson, praised Lizars' bravery in performing the operation, but his disappointing results resolved the journal's editor to continue cautioning against surgeons repeating the procedure. ${ }^{2}$ The Lancet, on the other hand, gave a more enthusiastic reception to Lizars' work. Still only two years old and founded on the radical agenda of its editor Thomas Wakley, who sought to challenge the conservatism and nepotism of the medical establishment, the journal implored its readers to cut through the prejudices of the profession and judge the operation relative to others already in existence. In keeping with its growing reputation for boldness, the journal claimed to see no reason why the operation should not be performed. ${ }^{3}$

Lizars' publication marked the introduction of the operation into the British public sphere. It hinted also at the increasingly polarised views of the medical community with regard to it. By the 1820s, the possibility of surgically extirpating the dropsical ovary was accepted by many medical practitioners to be at least technically possible. Empirical work by the obstetrician James Blundell, published in the Lancet in 1828, had built a more solid foundation for the practice of abdominal surgery based on experimental physiology. Blundell's experiment, in which he had removed ovaries, uteruses, spleens, kidneys and portions of the bladder from twenty-nine rabbits - eight of whom had survived-led him to believe that it was possible for the human peritoneum to tolerate injury and interference. ${ }^{4}$ Blundell concluded from his experiments that the ovaries, the uterus, the spleen and parts of the bladder could all be removed from the body. But it was the ovaries that remained the focus of surgeons' attention as practitioners sought to build on the work of McDowell and Lizars. Interest in removing the other organs was not pursued; innovation required greater motivation than simply technical feasibility.

Coupled with successful cases being reported in London, as well as from Germany and America, the operation hovered at the boundaries of acceptability. ${ }^{5}$ One doctor in America in 1822 claimed already to be teaching students how to carry out the procedure. ${ }^{6}$ Those who continued to advocate medical treatments of ovarian disease increasingly faced scepticism from their peers. When St. George's Hospital physician Edward Seymour, for example, published a lengthy tome on ovarian pathology and physiology in 1830, he faced criticism for proposing treatments that deviated little from the customary cluster of therapeutics, such as diuretics and purgatives, employed by practitioners to treat a whole host of diseases, and 
for not instead investigating more radical cures. ${ }^{7}$ A more nuanced nosology of ovarian tumours was also developing, which further teased apart ovarian disease from sweeping categorisations of 'dropsy'. 'Dropsical' swellings in the ovaries could be cysts, sometimes comprising a single chamber, but more often made up of multiple small sacs of fluid; they could be hard and malignant or soft and jelly-like. Their contents ranged from watery fluid to thick, opaque substances, to matter that resembled powdery coffee-grinds; ovarian disease manifested in such disparate ways that generic treatments like tapping and diuretics simply seemed at odds with pathological understandings. The ineffectualness of such treatments for ovarian disease only reinforced the latter's distinctiveness as a category of pathological disorder; indeed, the Edinburgh Medical and Surgical Journal questioned the validity of using the term 'dropsy' at all when describing the ovaries, arguing the term was erroneous when used to classify their diseases. ${ }^{8}$ The inadequacy of standard treatments was a view James Blundell communicated to his students in his lectures on midwifery at Guy's Hospital at the tail end of the 1820s. Speaking about tapping in a lecture on midwifery, he declared to his class, 'the more I have seen of this operation, the more I have felt inclined to whisper to myself, when the surgeon has taken up his instrument, "I wish he could do something better".?

A cautious optimism lingered around the new operation but its considerable hazards remained evident. Failed cases still outstripped successful ones, and experiences like that of Lizars showed the range of difficulties that might be encountered, from misdiagnosis to the presence of adhesions, which would render it impossible to remove the organ. Surgeons stood at a crossroads. Could an operation with so much potential for complication, and which required entering the unknown territory of the abdomen, ever be admitted into established practice? The debate was carried and amplified by the weekly medical press, itself a novelty of sorts. The establishment of the Lancet in 1823 precipitated the arrival of a multitude of other weekly and fortnightly publications in Britain over the next few decades. Together they sped up the circulation of medical knowledge, generating a culture of public correspondence through their columns and providing a space for clinical case reports, medical politics and informal dialogue which glued together the profession. It is to fundamentally misunderstand the medical press to consider it a neutral 'mirror' upon medicine. Medical journals shaped and led debates, implicitly relayed the medical and political inclinations of their editors and publishers and guided their audiences through the latest discoveries and innovations. Through this latter function, the medical press entered 
a reciprocal relationship with those performing the new ovarian operation, enabling surgeons to bring their experiences and results under the scrutiny of the medical community. In exchange, the operation proved a newsworthy and controversial topic, of the type that the medical press thrived upon. There was a thirst for knowledge and news of the operation within the medical profession. The question of the operation's justifiability could not, after all, be judged until its risks were adequately understood. But what methods of analysis best interpreted and conveyed the risks of what was irreducibly a practice-based innovation? The medical press made it possible for there to be a plethora of modes of representation. This complicated searches for the truth and reality of the procedure as British practitioners tried to make sense of the moral, technical and professional concerns that came with the growing use of a novel operation in practice.

In the rest of this chapter, I consider three different aspects to the representation of ovarian surgery in the press between the early 1830s and the 1850s when the justifiability of removing ovaries was the subject of intense debate. In the first section, by way of setting the scene, I give a brief overview of the place of ovarian surgery in British medicine in the 1830s, before going on to consider how, during this time, it could be represented as both progressive and regressive. How were these differing representations situated in a medical culture where changes in anatomy, pathology and professional politics were shaping ideas of 'progress' in surgery? I go on to consider the place of what I term 'emotive accounts' of ovarian operations that emerged in the medical press, particularly during the 1840s, as the operation began to be performed by numerous practitioners in London, bringing it closer to the metropolitan hub of English medical practice. Reports of ovarian surgery in the medical journals were distinctive in their verbosity and in their strong conveyance of the patient's narrative, constructed to elicit an emotional response from readers. This played heavily into discussions regarding responsibility in surgery and even blame. Moreover, the women who underwent the procedure were not necessarily represented as passive participants. Their active role in agreeing to the operation, as well as their behaviour before and especially after it had taken place, played an important role in the way the operative experience was presented to the rest of the medical community, both by those who advocated the operation and by those who made it their business to prevent it becoming established practice. I then turn to the role of statistics in accounts of the procedure, 
considering how statistical and 'emotive' representations of the operation complemented, challenged and complicated one other. Quantifying data, it has often been argued, became central to medicine around the middle of the century, and the use of statistics in settling the question of ovarian surgery's justifiability might be assumed to be simply another reflection of the shift towards 'scientific' medicine at this time. But, practitioners wondered, how useful were numbers in representing surgery? Could they provide a definitive answer to the justifiability question? And how could they represent the moral uncertainties that hung over the operation?

\section{Progress or Culpable Homicide?}

In 1837, a paper by William Jeaffreson, a surgeon practising in the small market town of Framlingham in Suffolk was published in the Transactions of the Provincial Medical and Surgical Association. In it, Jeaffreson described the case of Mrs. B, a long-time patient of his who had laboured under suspected ovarian dropsy for some years, the condition causing complications in two pregnancies. As was typical, Mrs. B's tumour had been slow growing at first, before beginning to rapidly enlarge, leaving the patient in considerable pain and leading Jeaffreson to offer his distressed patient 'the one chance which I thought remained, by operation, candidly stating its probable hazard'. ${ }^{10}$ With the final decision apparently left to Mrs. B-the significance of which will be explored in more detail later in this chapter-a date for the operation was set. A small incision of about an inch and a half in length-much smaller than the type made by Ephraim McDowell and John Lizars-was made between the navel and pubes. The diseased sac, once located, was punctured and drained of twelve pints of fluid before being seized and cut away. After a week, Mrs B was considered cured and out of danger. Jeaffreson went on to perform four more similarly successful procedures for ovarian disease, while colleagues of Jeaffreson from the East Anglian medical community reported successful cases too. ${ }^{11}$ Together with the Tonbridge practitioner William West, who had four cases, two of which had good outcomes, provincial practitioners led the way in ovarian surgery. ${ }^{12}$ Like McDowell before them, Jeaffreson's and West's geographical locations arguably spurred on their use of novel and risky procedures. Away from the more tightly bound medical communities of London and Edinburgh, the practices of provincial doctors were less scrutinised. 
Jeaffreson's operation received positive reviews from some corners of the medical press. Advocates of the operation praised Jeaffreson for his bravery, one claiming the surgeon was 'opening to us a new era in the surgery of the abdomen'. ${ }^{13}$ But with their publication the cases were also open to critique. Two objections to the operation were put forward with increasing regularity: the first was the very real possibility of misdiagnosis, which had been visibly highlighted by John Lizars' erroneous operation upon a woman who had had no ovarian tumour at all. Performing a dangerous operation when there was a high chance of death was an ethical quandary in itself; that the pursuit might be entirely in vain was flagrantly immoral. The second criticism centred upon the propriety of performing the operation, given that it was possible for a patient to live with the condition for some time, whereas the operation 'may carry them off in a few hours'. ${ }^{14}$ The justifiability of using surgery for what was construed as a chronic rather than an acute illness was at the heart of the controversies over the operation.

In the 1830s, there was no more outspoken opponent to the procedure than the surgeon Robert Liston. Liston, who was probably the most famous operator of his generation, had come from Edinburgh to London in 1834 when he was appointed Professor of Surgery at University College London. He was an excellent anatomist and a skilful surgeon of external diseases, including tumours. Much of his considerable fame was cultivated from his dazzling displays of operative skill, where he showcased a striking speediness in his surgical performances, and where he excelled in daring procedures such as excision of the large jaw, removal of scrotal tumours and amputations of the thigh. Liston's surgical innovations tended to spring from an audacious self-confidence in his own operating skills, a characteristic that at times led to him perpetrating grim errors in his practice. ${ }^{15} \mathrm{He}$ espoused simplicity above all else as the key to successful surgery. ${ }^{16}$ In his 1837 manual, Practical Surgery, he communicated his 'plain, common-sense view of the most important injuries and diseases which are met with in practice', which he claimed were 'unencumbered by speculations or theories'. ${ }^{17}$ In 1846, a year before his death, he became the first surgeon in Britain to perform an operation under anaesthetic ether, cementing his reputation as one of the nineteenth century's more influential surgeons.

Liston was not unusual at this time in troubling himself over abdominal surgery, but he was notable for the ferocity of his opposition to it, which reflected his brusque persona. In Elements of Surgery, 
first published in 1831, Liston claimed that John Lizars was 'indictable for culpable homicide' for the fatal operation he had performed. The unfortunate women who had undergone the procedure he described as 'sacrificed to a desire for false reputation'. ${ }^{18}$ This was not the only time the operation was linked criminality by those who opposed its use. During the first half of the nineteenth century, numerous surgeons who performed the operation found themselves threatened with criminal charges. One American surgeon, Walter Burnham, recounting in 1879 his early experiences with the operation, recalled how he had 'many times been threatened with prosecution for manslaughter' and that he had 'heard one of the ablest Professors in New York denounce all ovariotomists as "deserving to be hung". ${ }^{19}$ British surgeons experienced the same threats. ${ }^{20}$ As shall be explored in detail later in this chapter, involvement in the operation came with serious risks to one's career.

For Liston and others who opposed the operation, there was nothing to suggest that opening the abdomen was the beginning of a new era, let alone a sign of progress in surgery. Rather, they used evocative language to depict it as a regression; the famous term, 'belly-rippers', which Liston coined to describe those who performed ovariotomy, suggested a throwback to baseness and butchery, while the allusion to female 'sacrifice' Liston made conjured up images of slavishness to unthinking ritual and of unnecessary death, quite contrary to any notion of progress. So powerful was sacrifice as a metaphorical trope that early proponents of the operation also used it in their representations of the procedure, instead describing the sacrifice of women to the untamed ravages of disease, left to die rather than being offered a chance of life. ${ }^{21}$

Liston was joined in his disavowal of the operation by William Lawrence, surgeon to St. Bartholomew's Hospital. The way Lawrence conveyed his opposition to the operation requires us to consider in more detail how 'progress' elicited complex meanings in surgery. The historian Peter Stanley has depicted the 1830s as a period when 'the only way to make a name as a surgeon...was by performing operations, and young men hoped that by performing an operation first, more daringly or more spectacularly, it would enhance their reputation'. ${ }^{22}$ An oft-made supposition is that pre-anaesthetic surgery was a haze of speed and spectacle, and that surgeons were at liberty to innovate freely. ${ }^{23}$ But any radical new procedure in surgery was tempered by the continued deference of 
surgeons to an ideal of reducing the number of operations performed, which, it was believed, would be increasingly possible as surgical pathology improved. It was, after all, the science of surgery rather than its manual aspects that many surgeons, concerned about their professional standing, wished to promote. ${ }^{24}$ As Adrian Desmond has shown, during the 1820s and 1830s, British physicians and surgeons were reflecting intensely upon broader notions of progress, reform and radicalism in the organisation and philosophical underpinnings of medicine. The explosion of medical-professional politics during this time, as reformers like Thomas Wakley castigated the bloated medical corporations and hospitals for their elitism and nepotism, was closely intertwined with the transmission of radical new medical theories into British education. This included Lamarckian ideas of philosophical anatomy, which stressed commonality between organisms, rather than hierarchy, enabling radical medical men to emphasise a universal thread of progressive egalitarianism in both anatomical theory and the organisation of medicine. ${ }^{25}$

Conservative members of the profession worried about the unwelcome importation of French philosophies of medical practice. Some believed it explained an increase in bold and daring operations occurring in Britain, particularly gynaecological and obstetrical ones, borne of the influence of a continental culture that prided itself on risk and novelty. In 1828, the politically conservative London Medical and Physical Journal claimed that 'some of the operators of this island have shown an anxiety to import such operations from the continent or to invent others which vie with them in boldness'. This was no doubt in part an allusion to the French enthusiasm for caesarean sections, which were performed more often on the continent than in Britain. ${ }^{26}$ But the journal also landed upon John Lizars' operations to remove ovaries as an example of surgical boldness. ${ }^{27}$ In actuality, in the early 1830s, ovarian surgery was still roundly disapproved of by French surgeons. But the operation was sufficiently controversial that conservative members of the profession strove to represent it as a French idea and thus use it to support their notion that British medical men were vulnerable to the influence of dangerous foreign radicalism.

Despite the claims of the London Medical and Physical Journal, progressivist medical politics among surgeons did not necessarily extend to radical modes of practice, as William Lawrence exemplified. Although by the 1830s Lawrence had virtually renounced his political radicalism after being elected to the Council of the Royal College of Surgeons of 
England, in the decades preceding that, no other London surgeon had had such a profound impact on medical philosophy. Lawrence had been an outspoken critic of the lack of democratic representation for general practitioners, who made up the bulk of the profession, and was a close ally of Thomas Wakley. His deep attachment to controversial French anatomical theories also saw him adopt a materialist viewpoint that was condemned as blasphemous. Throughout and beyond these controversies, Lawrence exercised an enormous influence as a surgical educator. A gifted orator, his lectures were warmly received by his students at St. Bartholomew's. ${ }^{28}$ Lawrence promoted increased unison between physic and surgery, and in his first lecture of the winter season of 1829, he emphasised the fluidity of the boundaries erected between the internal and external body, deriding the capriciousness of such a division when all diseases were so closely connected by a general physiology and pathology. 'How deep would the domain of surgery extend, according to this view?' Lawrence pondered with more than a hint of sarcasm, 'half an inch or an inch?' ${ }^{29}$ Lawrence emphasised the need for internal causes to externally recognisable ailments to be part and parcel of surgical education.

Strikingly, Lawrence's radical aspirations did not extend to any desire for operative surgery to foray further inside the body and Lawrence continued to equate surgical practice with external disease. ${ }^{30}$ Like Liston, Lawrence viewed ovarian surgery as bloody, brutal and backward. $\mathrm{He}$ reacted incredulously to the possibility of removing ovaries, citing the difficulties in diagnosing what disease lay beneath, which he believed made the operation unjustifiable. In a lecture in 1830, Lawrence subtly married the idea of the large abdominal incision with the act of dissecting the dead, commenting caustically that 'the operation merely requires an incision to be made through the integuments of the abdomen, extending from the pubes to the ensiform cartilage; exactly the same kind of cut that you would make in examining a subject after death'. ${ }^{31}$ The same idea was later echoed by Liston, who, in a lecture published in the Lancet, quoted the macabre poetry of seventeenth-century satirist Samuel Butler to describe the ovarian operation: 'as if a man should be dissected/to see what part is disaffected', Liston told his students. ${ }^{32}$

Liston and Lawrence's comments intimated repugnance at the opening of the sealed cavities of the living body, drawing an analogy between the violent interference which both dissection of cadavers and surgery of the abdomen required. Represented this way, the operation evoked all the horrors of human vivisection at a time when tension 
surrounding doctors' use of cadavers was growing. Just a year before Lawrence's lecture, the labourer and cobbler William Burke had been hanged in Edinburgh for his part in a series of gruesome murders he committed with his accomplice William Hare. The bodies of those they killed had been sold as dissection material to the surgeon Robert Knox. Knox was eventually cleared of any wrongdoing in the scandal, but his reputation never quite recovered. ${ }^{33}$ To prevent further, similar episodes, the Anatomy Act, passed in 1832, had given surgeons increased access to bodies, allowing them the unclaimed dead of the workhouses. But the Act, wrought with caveats, served only to stigmatise the bodies of the poor instead of criminals. Throughout the decade, tensions between the profession and the public remained high. The latter remained deeply suspicious of surgeons' practices with dead bodies. ${ }^{34}$

Certainly, some of the descriptions given by those performing abdominal surgery in the late 1830s were suggestive of an anatomical exploration of the living, fully conscious patient. Robert King, who had assisted William Jeaffreson in his first operation, reported to the Lancet on his numerous attempts at abdominal surgery in 1837. In 1834, King had made an eight-inch incision into the abdomen of forty-year-old Sophia Puttock, who was suffering intolerable pain caused by a suspected tumour:

To give greater facility for examination, the wound was enlarged in the direction of the lumbar vertebrae, for about four inches. The search was repeated most carefully, not only in the perpendicular direction, but upwards, towards the liver and small extremity of the stomach. Several of the gentlemen present repeated the attempt to find the tumour, but unsuccessfully. The kidney of the same side was handled, and appeared to be more moveable than natural, as it could be raised from its position nearly two inches. After the cavity of the abdomen had been exposed for two minutes, it was determined to reclose it, which was done without difficulty, by the common interrupted sutures. ${ }^{35}$

Puttock's abdomen had been cut open, allowing King to handle her abdominal organs, before he then invited his colleagues to insert their hands into her body to do the same. The operation could well have proved a useful anatomy lesson to King and his colleagues; indeed, King himself presented it as an important part of the operative experience. But such accounts also allowed individuals like Lawrence and Liston to use the imagery of dissection to represent the operation as a violation of the living body. ${ }^{36}$ 
In terms of how representations were constructed, there is a crucial point to be made here: that there was discordance between notions of progress in anatomy and those in surgery. While a surgeon like Lawrence could enthusiastically promote French methods of observation and practice over textbooks and lectures, as well as embrace radical ideas of anatomy and medical politics, this did not extend to countenancing the radical newness of abdominal surgery. Undoubtedly, this was in part a response to the very real risk of patients dying, as well as the delicate public reputation of surgeons, particularly in the light of the body-snatching scandals. But it also leads to more complex questions about connections in medicine that we often take for granted. For many surgeons, the new in fact did not always represent the progressive, nor was improvement in anatomy necessarily best represented by an expansion in the remit of surgery.

At the end of the 1820s, John Lizars' advocacy of ovarian surgery was described by the London Medical and Physical Journal as 'exactly the opposite to ninety-nine men out of a hundred'. ${ }^{37}$ By the end of the 1830s, little seemed to have changed. Further operations had occurred, but they remained few and far between and generally performed outside the medical metropolises of London and Edinburgh. During this time, powerful opposition to the operation was arising, which saw ovarian surgery represented by its detractors as contrary to surgical morality. Beyond the ever-present concerns regarding the hazards of the operation, competing representations of progress were at play. The operation had to be carefully situated within a medical world fraught with professional politics.

\section{Who's Responsible? Patients, Risk and Emotive Accounts}

Despite the powerful opposition of Liston and Lawrence, the early 1840s saw an uptake in the practice of the operation-or at least an increased reporting of cases - as it began to be performed by numerous London practitioners. Some of these operations, such as those by Charles Aston Key, Caesar Hawkins, Bransby Cooper and Benjamin Phillips, were one-offs. All but Hawkins' case had resulted in the death of the patient, and one can speculate that this may have prevented those practitioners from making further attempts. But there was also a small group of surgeons, including Samuel Lane, Daniel Walne and Frederic Bird, who had performed 
the operation multiple times and with greater success. Most cases were treated in private although occasionally the operation would be performed at a hospital. The most prolific operator of all, however, was Manchester obstetrician and surgeon Charles Clay, who commenced a long and unbroken series of the procedures in 1842, claiming in 1848 to have performed the operation forty times, twenty-six of which had been successful. ${ }^{38}$ These practitioners came from a range of professional backgrounds; Bird was a young, recent graduate from Guy's, Lane was a senior surgeon at St. Mary's, Walne was a less well-known but also relatively well-established London surgeon, while Clay was part of an elite of Manchester obstetricians. It was Charles Clay who in 1843 introduced one of his cases with a new word to describe the operation: 'ovariotomy', a term he claimed had been coined for his operations by his most wellknown supporter, the Scottish obstetrician James Young Simpson. ${ }^{39}$ The term was a misnomer-technically 'ovariectomy' would have been more accurate, as the ovary was completely cut out; 'ovariotomy', as Clay used it, implied only an incision. But nonetheless the word stuck, assured by the combined clout of Simpson and Clay.

At this point, the London Medical Gazette and the Medical Times rather than the Lancet were where the majority of cases of ovarian surgery were published. This was possibly a bid on the part of operators to avoid the acid tongue of Thomas Wakley, for by 1844 the Lancet, which earlier in the century had been a cautious advocate of the operation, had come out against the procedure, publishing a strongly worded editorial condemning its use. ${ }^{40}$ Choosing which journal to publish it was one of several factors surgeons needed to consider when opening up their cases to public scrutiny. Those who performed it were already in a precarious position, more especially if they were disclosing poor results. Crafting an account which was able to adequately convey one's experiences, the patient's journey, and which also carefully negotiated the ethics of the operation, was a delicate process.

It has been argued, not always convincingly, that it was in the nineteenth century that the patient's 'voice' began to disappear from medical accounts. The conversational, emotive style that characterised early modern narratives of illness was replaced by an altogether more dispassionate tone, dominated by the practitioner's (rather than the patient's) voice, something often closely aligned with the 'rise' of hospital medicine in the early part of the century. ${ }^{41}$ Clinician and 
historian Brian Hurwitz has described the style of the nineteenth-century medical report as involving a 'ruthless curtailment of patients' accounts and the denial of their agency within case reports...accompanied by a clinical attentiveness that focuses now on the normality of body systems'. 42

My argument here is somewhat different. It is rather that those practising ovariotomy both desired from others and were expected to provide richly subjective accounts of their own and their patients' experiences as well as ostensibly objective, statistical-based data. In this sense, I align more closely with the argument put forward by literary theorist Meegan Kennedy. As she contends, the case history, which had so long been a significant aspect of medical culture, was not merely ironed out or replaced by tools of 'objectivity' in the nineteenth century. Rather, the nineteenth-century case history faced 'a uniquely heterogeneous set of demands: it must produce both a fact and a story, represent both a disease and a person, display both the disinterested stance of the man of science and the physician's subjective insight' ${ }^{43}$ As we shall see in the next section, 'objective' statistical accounts of ovarian surgery were important. But surgeons were predominantly concerned with constructing-and journals with publishing-full, qualitative accounts that centred upon the patient narrative. These were conceived of as crucial to formulating an idea of how justifiable ovarian surgery was. They were used to convey emotional experiences that more objective accounts could not express, as well as to elicit equally emotive responses from professional colleagues. Given the ethical questions the operation raised, this style of representation was more prominent in cases of ovarian surgery than in other forms of surgery. The negotiation of responsibility between surgeons and patients was at the crux of these accounts.

Surgical responsibility has been a subject of interest to historians of late. Claire Brock's recent work on abdominal surgery in late nineteenthcentury Britain elaborates upon the divisions of responsibility between surgeons and their assistants, as operations began to be performed by surgical 'teams' rather than individuals. ${ }^{44}$ Like historians before her, including Regina Morantz-Sanchez, Brock also raises the issue of patient demand for ovarian operations in the latter part of the century, opening up the question of how far women could be deemed responsible for the outcome of operations (especially when they failed) and even in encouraging unnecessary procedures. ${ }^{45}$ This can be connected to previous work by Morantz-Sanchez on gynaecological surgery, which has contested 
the notion of the patient's disappearing voice in the nineteenth century, revealing instead the pivotal role some patients were able to play in the decision-making process. ${ }^{46}$

As I will elaborate upon in Chapter 5 , the issue of patient demand certainly became an area of increasing concern during the latter part of the century. But less is known about the patient role in ovariotomy during the middle decades. From our contemporary viewpoint, it is perhaps hard to conceive of demand for such an operation in the pre-anaesthetic era. Surgery at this time could be bloody, brutal, fearful and unimaginably painful. Moreover, a patient's power to demand certain plans of treatment would have been heavily dependent on their socio-economic status. In any event, there was patient demand for ovariotomy, propelled by the deep suffering and humiliation ovarian disease could cause. This factored heavily into the way surgeons presented their experiences of the operation. ${ }^{47}$ The operations which Frederic Bird, Daniel Walne, Charles Clay and others performed were by their own admission hazardous. Yet, as they represented it, it was not they but their patients who demanded they took place.

My concern is less about the material extent to which this was occurring, which it would be hard to determine, but rather how the patient role was used and amplified in surgeons' narratives of ovarian surgery to their advantage. Take a report published in the London Medical Gazette in 1840, sent in by the surgeon Benjamin Phillips about his twenty-one-year-old patient, identified only as 'A.D.'. Phillips began not with the case itself but with a lengthy preamble which saw him preparing his audience for the bad result he was about to reveal: 'unquestionably it is more agreeable to detail the results of the successful than the unsuccessful practice of our profession' he stated, 'yet it is equally incumbent on the practitioner to detail the one and the other' ${ }^{48}$ As Phillips saw it, there was a growing prevalence among surgeons for refusing to take responsibility for a bad outcome, the consequence of 'a desire men feel to find a cause of death over which they could not have control: and that is rarely difficult: the consequence of this is, that when they estimate the results of treatment, they exclude all cases where they can find reason for death independent of the operation or the treatment'. ${ }^{49}$

Yet as Phillips moved on to describe the case of A.D., a striking contradiction began to emerge in his account, as the surgeon began to subtly shift the responsibility for the case's failure to the patient and her family. Phillips began by conveying A.D.'s long journey towards the operation. 
A.D. had perceived an enlargement on one side of her abdomen many months before, which after a period of slow growth had begun to rapidly enlarge. With a prescribed cupping treatment proving ineffective, her case had been passed via Robert Liston on to the obstetrician Charles Locock. Whether Liston was aware of Locock's opinion of the operation is not known, but the views of the man he was sending her on to were quite the opposite of his own. Locock advised A.D. that both tapping and medicine would be useless and that there was only one hope. Phillips paraphrased Locock telling the girl that: "within the last four years an operation had been invented by which the cyst could be extracted; that if it succeeded her disease would be cured, and he strongly advised her to undergo that operation'. ${ }^{50}$

Exercising a degree of consumer power, A.D. once more switched doctors, determined to find someone who would not just recommend the procedure but also perform it. Her next doctor was of a similar opinion to Locock and at once referred her on to Phillips, who at last gave her the news she wanted: that he would undertake the operation. A month later, with A.D. in 'good spirits', ${ }^{51}$ Phillips performed the procedure with ten other medical men in attendance. The operation went well, with the ovarian sac easily removed and as Phillips had estimated, no adhesions were present. The pedicle, the small stem-like piece of tissue which contained nerves and vessels, connecting the diseased ovary to its blood supply, was cut and ligatured and the patient appeared to be recovering well. However, A.D.'s condition quickly took a downward turn. She began to experience agonising pain on the right side of her abdomen, to which morphia and opium made no difference. Blood oozed from the wound and frequent vomiting set in. A brief upturn in her health ('countenance very good') was followed by the ominous reporting of 'cholera-like symptoms'. She died soon after. ${ }^{52}$ A post-mortem uncovered two potentially significant pathologies: first, that the ligature which was supposed to have secured the end of the severed pedicle had failed to contain all the vessels; second, that the intestines were grossly ulcerated, which Phillips argued showed evidence of pre-existing disease. Phillips' call for surgeons to take responsibility for their mistakes seemed to dissolve under the weight of his own desire to clear himself of blame; it was also here that the verbosity of the account and the strong presence of the patient's voice were most useful to him. Phillips went on to suggest that it was A.D.'s intestinal condition that was the cause of death rather than the operation-the issue of the ligature he proceeded to completely ignore. 
Phillips revealed that subsequent conversations with A.D.'s mother had seen her admit to not informing him that her daughter was suffering serious bowel problems. When the mother had mentioned to her daughter just before the operation that she had not told Phillips of this, Phillips quoted the daughter's response to her mother as the following:

It is lucky, mother, that you did forget it, for I have been twenty times to-day, but do not say anything to Mr. Phillips about it, or he will put off the operation. ${ }^{53}$

Using the patient's 'own' voice, Phillips implicated A.D. and her mother's actions in A.D.'s death.

It was not unusual for blame to be parcelled out to patients in this way. In his third published case, Charles Clay made a similar assertion of blame in the case of forty-seven-year-old Mrs. Dillon, this time in regard to the behaviour of her and her family after the operation. On opening Mrs. Dillon's abdomen, Clay and his colleagues had found a malignant tumour with significant vascularisation. Deemed inoperable, as malignant tumours usually were, the patient's abdomen had been closed without any active treatment. On the morning of the fifth day of her recovery, Mrs. Dillon's husband had requested giving his wife a mixture of gin and garlic 'as she had been accustomed to take it for the wind', a request Clay denied. When later that day he visited the patient, she had become seriously ill and Clay found it impossible to reflect on the progress of the case...without suspecting some interference of the most unwarrantable description in the nursing, particularly when coupled with the wish to exhibit stimulants in the morning of that day'. ${ }^{54}$ Mrs. Dillon died six days after the operation and Clay placed the blame squarely with the family members who had been attending the patient, whom he believed had provided her with gin against his wishes. ${ }^{55}$

Such accounts encouraged readers to think deeply about divisions of responsibility in surgery. Where did fault lie when an operation went wrong? Was a fatal outcome always the surgeon's responsibility? Or could blame lie with the patient or those who attended them after? Surgical operations are often assumed to be discrete events in which the role of different actors is self-evident. Phillips' and Clay's reports instead pointed to the malleable nature of responsibility and blame in surgery, and the porous boundaries between the operation itself and events that occurred before and after that might influence its outcome. 
As was seen in the case of A.D., it was not only a patient's consent to the operation that was described but, often, their pursuit of it as well. In many of these cases, the patient was depicted as the driving force and the surgeon as the reluctant possessor of potential healing powers; an impartial adviser to the suffering woman. This was exemplified by Clay's first case, a woman named Mrs. Wheeler in 1842:

My patient began to express herself earnestly desirous of an operation respecting which I neither persuaded her to, nor dissuaded her from, but faithfully detailed to her the magnitude of the means she sought, pointed out the particulars of every case on record, with the results, and rather if anything depreciated than added to the chance of recovery. Still she was determined I should operate. ${ }^{56}$

And indeed in Mrs. Dillon's case, which ultimately had ended fatally, Clay retrospectively characterised himself as having had his own sense of judgement overpowered by the patient's determination:

In vain I argued that her case had not the same prospects of success as the others preceding hers and that if it was performed the chances were greatly against her; her importunities at length prevailed, and I somewhat reluctantly consented to operate. ${ }^{57}$

Husbands and male relatives were conspicuous in their absence in narratives of patient consent. It was stressed by surgeons that the women made the final decision, and that their subjective understanding of their own lived body potentially outweighed the surgeon's own feelings on the matter. Many case reports emphasised the bodily pain that might compel women with the condition to seek help as well as the greater impact of the disease upon their self-image. In the case of A.D., for example, Phillips stated that her main motivation for seeking help was the stir that her changing shape was causing among her peers, the surgeon commenting that 'the tumefaction was so far increased as to have become apparent externally, and subjected her to remarks which distressed her a great deal'. ${ }^{58}$ It was likely that, like countless other women, A.D. was also suspected of being pregnant. Daniel Walne's third and youngest patient, 'A.K.', was reported to have echoed similar concerns. The nineteen-yearold girl and her family were distressed by remarks from A.K.'s teacher and later her employer about her unusual and 'matronly' appearance; indeed, 'her size excited so much observation, and caused so many unpleasant 
remarks...that she was obliged to return home'. ${ }^{59}$ The interplay between illegitimate pregnancy and ovarian tumours and its attendant consequences - social stigma and even a detrimental effect on employability and marriageability-weighed heavily on the minds of younger patients with the condition. Even if pregnancy was not suspected, the oddity of appearance which the condition could cause - a grossly swollen belly, often coupled with a swelling of the legs or emaciation of the rest of the bodycould be distressing enough, a fact that was emphasised by operators. ${ }^{60}$ Walne's first case, fifty-eight-year-old Mrs. F., was moved to seek treatment because she had become 'unpleasantly remarkable'. ${ }^{61}$ Surgeons constructed accounts that fleshed out patients' experiences, beyond the clinical points, and detailed the impact of the disease on their quality of life. ${ }^{62}$

The role of patients in initiating surgical encounters also proved useful material for those against the use of ovariotomy. Samuel Ashwell, lecturer in Midwifery at Guy's, spoke out vehemently against the operation in the 1840s. Following the publication of his monograph, A Practical Treatise on the Diseases Peculiar to Women (1843), Ashwell's views on the operation began to filter into both the British and American press. Journals picked up on his description of an encounter with a sixty-two-yearold woman who had travelled a long distance to visit him in London 'anxious to have extirpation performed'. The woman 'had never been tapped, although ovarian dropsy had existed for more than half her life'. Somewhat dismissively, Ashwell claimed that 'there was scarcely any suffering beyond weight and pressure, although the tumor was of immense size and partly solid' and that 'in such a case it would have been highly culpable to have operated; and yet a surgeon over-zealous about the removal of ovaries had induced the firm belief that it ought to have been done'. ${ }^{63}$ In this case, Ashwell claimed to have made the woman sensible to the dangers of the operation and that she had changed her mind. But in another, that of a twenty-two-year-old woman who had approached him, the patient had gone on to find another surgeon to perform the operation, only for it to prove fatal. 'Many years might have been added to her existence', noted Ashwell regretfully. ${ }^{64}$ For Ashwell, patient demand was to be quelled and not acquiesced to.

Mirroring the use of patient narrative, the small band of men who were willing to remove ovaries could also shift around ideas of responsibility when the operation was not performed. An article in the Medical Times in 1851 by Frederic Bird barely concealed the anger he felt about a young patient on whom he had wished to perform ovariotomy. 
Miss F. was just twelve years old when she first perceived an abdominal swelling. After numerous encounters with a variety of physicians and surgeons, Bird met Miss F. three years later. Describing her as 'possessed of remarkable vivacity and intelligence', who complained little about her illness, ${ }^{65}$ Bird appeared openly moved by the plight of the girl, who had by this point developed serious curvature of the spine from where the pressure of the growth was bearing down. Much to Bird's chagrin, Miss F.'s original physician, Robert Lee, was of an opinion that stood in stark contrast to his own. Lee believed an operation inadvisable and, as Bird reported it, 'with a natural desire to spare their child useless suffering, the parents were influenced by the apparent doubt based on Dr. Lee's opinion'. ${ }^{66}$ Thus, the operation was not agreed to. A year later, Miss F.'s parents changed their mind as the state of their daughter's health became increasingly desperate and Bird was asked to perform the operation. But Miss F. had become too weak to be operated upon and she died a few months later of the disease. While Bird never directly implicated Lee in her death, it was clear that he believed it was the latter's opposition to the operation that was at fault. 'If no other lesson be taught by this case' Bird warned, 'it must at least be conceded, that, as extirpation could have been performed, so might life have been preserved'. ${ }^{67}$ The dangers of the operation meant that its performance could be represented as a liability, morally and professionally, but so too could the absence of its performance potentially imply a lack of responsibility on the part of the doctor to alleviate a patient's pain, and to take a chance with the only operation that might save their life.

As Flurin Condrau has succinctly put it, taking a patient's medical history most often 'results in a medical construct based on information coming from the patient, while being clearly governed by perceptions, categories and the language of medicine'. ${ }^{68}$ Even more so, one might argue, when further mediated through journals aimed at a predominantly professional medical audience. The use of the patient's narrative to reinforce the justifiability of undertaking the procedure is translucently apparent in these accounts. The voices of A.D., A.K. and other patients were deployed by surgeons as part of a damage-limitation exercise. Evocative and dramatic narratives of their encounters with patients reinforced surgeons' characterisations of themselves as following their moral conscience; the product was reports in which the ethical aspects of the operation intentionally weighed heavily upon the reader. 
It would be inaccurate to assume that because the expected audience for these reports would have been a medically educated one they would have responded only to objective facts. It plays into a broader historiography that has posited objectivity and dispassion as inherent to nineteenthcentury medicine, where emotion was to be exorcised from surgeons' outward representations of themselves. But recent scholarly work has sought to challenge the notion of clinical dispassion. Michael Brown has argued that pre-anaesthetic surgery must be contextualised within the broader milieu of the early nineteenth century, during which enlightenment values of sensibility and sympathy laid the foundation for Victorian sentimentality. ${ }^{69}$ Historians like Peter Stanley have argued this hindered rather than helped surgeons, as they sought to repress the expression of emotion in an effort to stay true to scientific objectivity. ${ }^{70}$ But as Brown has amply evidenced, surgeons very frequently wrote discourses of emotion into their work and used it to build a professional culture that espoused compassion. ${ }^{71}$ Under these circumstances, it is plausible to assume that surgeons like Phillips, Ashwell and Bird wrote the accounts that they did so as to elicit emotional responses to support their cause. The medical press, no mere storehouse of clinical knowledge, but a commercially driven enterprise always looking for appealing and interesting content, authenticated and published these accounts.

The moral quality of the 'new' operation was so intertwined with its performance, that to sever the connection between the two was neither possible nor desired. Indeed, it is telling that when James Young Simpson set an examination question on ovariotomy for his students in the late 1840s, the question did not require simply an answer of technical facts, but instead asked the student to answer whether the operation was 'justifiable or not justifiable', provoking an implicit moral judgement to be made by the examinees. ${ }^{72}$ Ovariotomy was not only a question of technical innovation, it was a question of ethics too, and both advocates and opponents sought to recognise this in the way they represented their experiences and understandings of the operation.

\section{'An Eminently Uncertain Operation': Ovariotomy and the Trouble With Statistics}

By the early 1840s, a number of British practitioners willing to perform ovariotomy, but its standing remained precarious. The Medical Times saw the operation as justified, describing it in 1844 as 'far too 
important an innovation in surgery...to be lightly given up because it has not received the favour of a journal or two' ${ }^{73}$ The London Medical Gazette, which some years before had been vocal as to the unsavoury 'French' roots of the operation, stated that they now held a neutral position on the matter. ${ }^{74}$ But other medical journals remained resolutely opposed. The Lancet, as we have seen, publicly stated its position against it in 1844 and in the same year The Medico-Chirurgical Review also condemned it, disparagingly describing ovariotomy as 'the surgical subject of the day. It is the fashion just now to open the abdomen and cut out the ovary. It was the fashion last year to lay violent hands on every squinting man, woman and child, and cut his, her or its eyes out' ${ }^{75}$ 'Fashion' implied limited temporality, even faddishness. Just as reckless surgeons had been unnecessarily preoccupied with new eye operations the year before, ${ }^{76}$ so now they focused on an equally useless procedure upon the ovary. Others insinuated that it teetered dangerously close to the realm of quackery, vying with mesmerism and hydropathy in its controversy. ${ }^{77}$ But for many critics it was not just the operation itself that was the issue, it was how to make sense of the plethora of cases now streaming into the public arena. How could a decision about the operation be made, the profession fretted, if data on it were untrustworthy, incomplete or confused? Some began to formulate statistics from the cases published in a bid to bring closure to the ovariotomy debate; 'statistics will settle the question' the obstetrician Fleetwood Churchill declared confidently in $1844 .{ }^{78}$

The role of statistics in medicine is a path much trodden by historians. In surgery, Ulrich Tröhler has shown that the use of statistics stretches back farther than we often assume and that they were commonly used in the eighteenth century. ${ }^{79}$ But Ian Hacking's contention that it was during the nineteenth century that statistics began to permeate most elements of Western society through a powerful intertwining with print culture-what he describes as an 'avalanche of printed numbers'remains convincing. ${ }^{80}$ This is not to say that the medical profession quickly and unquestioningly accepted statistical methods. Throughout the eighteenth and nineteenth centuries, there were many in the medical profession who were not convinced by the usefulness of statistics, nor did they like what it represented about medicine - that it was, perhaps, more science than art and that it reduced their patients to mere numbers. ${ }^{81}$ But in the mid-nineteenth century, statistics figured more prominently in medical culture than ever before-in part because the expansion of hospitals enabled the collation of greater numbers of cases. 
The apparent 'rise' of statistics has sometimes been conceptualised as part of a wider history of risk, although that there might even be a history of risk to be found in the nineteenth century is a thorny issue. 'Risk' after all is often considered to be a twentieth-century phenomenon, associated with the increasing use of epidemiology to investigate the probabilistic aspects of illness on a mass scale, as well as with the expansion of the life insurance industry. ${ }^{82}$ Etymologically, too, use of the word 'risk' increased exponentially in the mid-twentieth century. For these reasons, discussing notions of risk in the nineteenth century has been considered presentist. ${ }^{83}$ While one must avoid conflating nineteenth-century concepts of risk with modern ones, surgical risk-as in measuring the likelihood of a fatal outcome-was very real, both as concept and as a term in nineteenth-century surgery. ${ }^{84}$ As Patricia Jasen has argued, historians' fears of presentism may stem from understanding 'risk' only by what it means today, when a more useful approach would be to understand the 'different languages of risk' that there have been, including the way risk was understood by the patient. ${ }^{85}$

How risk was represented statistically in regard to ovariotomy has been somewhat subsumed by historians' interest in the quantification of another surgical innovation of the 1840s: anaesthesia. Martin Pernick cautions against assumptions that anaesthesia was the main reason for an increase in operations in general; he nonetheless argues that in the case of gynaecology, and particularly ovariotomies, anaesthesia 'did indeed lead to new and more untested operations' and that before 1846 'ovariotomy had been done only as an heroic last resort' ${ }^{86}$ Aside from Pernick's anachronistic depiction of ovariotomy, ${ }^{87}$ his argument that there was a major division between ovariotomy pre- and post-1846at least when applied to Britain-is debatable. While the introduction of chloroform was welcomed by most performers of ovariotomy as an important aide to their operations, ${ }^{88}$ there is little evidence from the 1840s to attest to ether and chloroform either improving confidence in the operation among its sceptics or substantially increasing the number of operations being performed. In Britain at least, as the enthusiasm for anaesthesia began to cool soon after its introduction into practice, fears quickly set in over its role in encouraging dangerous and unnecessary operations. ${ }^{89}$ Its use in ovariotomy only added fuel to the fire as critics speculated that operations would now be performed even more recklessly. ${ }^{90}$ 
Ian Burney has argued that the introduction of anaesthesia was a prime example of the emergence of surgical risk in the nineteenth century and the use of statistics in calculating the risk of anaestheticrelated deaths as exemplifying the 'medical utilitarianism' that pervaded at the time. ${ }^{91}$ But the use of statistics to represent ovariotomy should not be read in the shadow of anaesthesia. Not only did ovariotomy statistics precede the introduction of anaesthesia in 1846 but the innovation under scrutiny was quite different: a surgical procedure, rather than a process ancillary to the actual operation, as anaesthesia was. This impacted on the process of statistical representation, as too did the unique status many ascribed to ovariotomy in terms of both its technique and objective.

It was Charles Clay's publication of his first five operations as a standalone pamphlet, Cases of Peritoneal Section, in 1842, which seemed to first draw the medical community's attention to the statistics of ovariotomy. ${ }^{92}$ At the end of the pamphlet, Clay had collated a list of all known large incision ovarian operations including his own (thus differentiating it from small incision procedures like that carried out by William Jeaffreson in Framlingham). As Clay calculated it, there had so far been ten successful cases and one failed case of the operation. ${ }^{93}$ His statistics, however, were met with derision. In a vicious review of the pamphlet, the British and Foreign Medical Review (later re-named The Medico-Chirurgical Review) tore apart his methodology, the reviewer pouring scorn upon the way Clay had grouped his own fatal outcomes. Clay, it seemed, had chosen not to count his two fatal cases, those of Mrs. Dillon and Mrs. Hardy, because he had operated upon them only to find tumours that were not ovarian but were either uterine or of an 'anomalous' nature; thus, Clay had seen fit not to count them at all in the statistics of his operations. Clay's approach outraged the Review. In a testament to the power that journal editors wielded in shaping representations of the operation, the Review re-jigged Clay's table of statistics into two tables that they claimed provided more accurate data: one table of completed operations and another of operations where no ovarian tumour had been discovered, or where the operation had had to be abandoned because of complications. The reviewer also attacked the validity of Clay's other data regarding successful cases. His inclusion of Jean-Baptiste Laumonier's 1783 case was discounted by the Review, who claimed Laumonier's patient Louise Lagrange had suffered from an abscess rather than an encysted ovarian tumour (somewhat contradicting their outrage at Clay's own exclusion of cases with a different pathology). 
Ephraim McDowell's successes were also, it seems, still being met with incredulity, the Review suggesting his operations 'stagger[ered] belief'. 94 Doubt was also cast on the validity of including John Lizars' apparently successful case, since the second ovary in the surviving patient was believed to have been diseased but not removed. The Review was clear in its dislike for the operation, but that these three particular operators came under so close a scrutiny spoke also to changing notions of what could be counted as valid evidence in surgery. In the eighteenth century, the boundaries between historical and contemporary data had blurred; as we have seen in Chapter 2, anecdotal evidence from the ancient world had played a role in validating the removal of the ovaries. By the 1840s, with Clay's statistics under scrutiny, older examples, unpoliced by contemporary British observers, were being discounted by critics.

Just a year later, two further statistical tables were published, one by the surgeon Benjamin Phillips in the Medico-Chirurgical Transactions and a second by the obstetrician Fleetwood Churchill, first published in the Dublin Journal of Medical Science, before being reprinted in The Medico-Chirurgical Review. ${ }^{95}$ Phillips, following the fatal result in A.D.'s case, had turned his back on the operation. He had become vocal in his belief that the results of unsuccessful ovariotomies were being held back and that this was erroneously giving the impression that the operation was safer than it was. ${ }^{96}$ Phillips inferred that multiple practitioners were choosing not to reveal cases where there had been a fatal outcome. He supported this contention by including in his table four cases (the surgeons described by the anonymous initials 'A.B.', 'C.D.' and so forth) that had never been publicly recorded in Britain but with which he was 'acquainted'. Three had resulted in death. Phillips insinuated that he knew of a number of other failed cases too, performed by surgeons who had already published on their successes but had failed to report those where the patient had died; he did not include these in his own statistics, implying instead that if these surgeons were honourable they would reveal their failed outcomes in due course. ${ }^{97}$ By stating that he had omitted such cases, Phillips was drawing attention to the limitations of his own statistics in accurately conveying both the number of ovariotomies performed and the procedure's relative risk. If, as Phillips asserted, a multitude of dangerous operations were going unrecorded, this was a worrying thought indeed, for it suggested the widespread and unchecked use of a dangerous innovation. 
The contemporaneous table constructed by Churchill further suggested that confusion was already present in the project to construct a 'true' statistical representation of ovariotomy's risk. Churchill's table differed considerably; it excluded several cases that Phillips had added to his, as well as including one-the contentious Laumonier case-that Phillips had not. The two men also calculated their mortality rates differently. Phillips had determined his by looking at how many times the diseased organ had been successfully removed from the patient and how many had then gone on to recover-only with both these elements in place did he believe the operation could be regarded as a success. Using this, he determined that there had been thirty-five successes out of eighty-one attempts, giving a success rate of forty-three per cent. Churchill had collated sixty-six cases and stated that there had been fortytwo recoveries and twenty-four deaths, giving an overall survival rate of sixty-four per cent. In cases where the ovary had been successfully removed (he counted forty-nine cases), a success rate of sixty-seven per cent was given. ${ }^{98}$

How ovariotomy statistics could be related to other major operations raised further divisions. For proponents of the operation, making such a comparison was vital to their cause. If ovariotomy's risk could be shown to be similar to those of other 'capital' operations, ${ }^{99}$ as many believed it was, then why should it be held in more disregard and fear than other procedures? ${ }^{100}$ Opposition to the operation, Charles Clay argued, stemmed from an illiberal and conservative streak in the medical profession, happy to cut off legs at the thigh and tie major arteries because these were 'established' practices, but unable to countenance the new. Clay believed it was the excessive and unproven fears about entering the peritoneum that prevented ovariotomy's establishment, an opinion that was probably well founded given the repulsion Robert Liston and others professed at the opening of the abdomen. ${ }^{101}$ Most questioned the validity of comparing ovariotomy with other operations; ovariotomy was a procedure based on choice, quite different from amputation and aneurysm, which were indispensable, emergency treatments. Supporters of ovariotomy like James Young Simpson claimed that if the meaning of a 'capital' operation was going to be scrutinised in this way, then other operationslithotomy or tying an aneurysm-could equally be described as operations of choice for conditions that could be lived with for years. ${ }^{102}$ But Simpson's argument largely fell on deaf ears; ovariotomy was inherently 
different because, as one critic put it in a letter to the Lancet in 1857, it was against 'surgical instinct'. ${ }^{103}$ Opening the abdomen and entering the peritoneum was so wildly different from performing a lithotomy, amputation or other 'classic' surgical operation that it simply rendered it incomparable.

While both advocates and opponents took an interest in the quantification of ovariotomy, statistical tables-or at least published oneswere more commonly constructed by opponents. Through one man, the aforementioned obstetrician Robert Lee, statistics came to be a powerful tool for those who remained sceptical about the operation in the 1850s. Lee in fact was a fine example of how statistics were constructed when one already had a firm opinion of the operation in mind. A Scottish-born but London-based practitioner, Lee had by the late 1840s built up both a considerable private practice and a powerful reputation as an author, lecturer, anatomist and physiologist. ${ }^{104} \mathrm{He}$ worked relentlessly in his numerous fields of interest and was well respected, although during his career he was involved in a number of well-publicised spats, including a lengthy dispute with Thomas Snow Beck during the 1840s over which one of them had ascertained correctly the anatomy and physiology of the uterine nervous system. Lee was a known traditionalist in his approach to surgery and especially in his distaste for major operations in obstetrics and gynaecology. From the late 1840s, Lee castigated the use of caesarean section in his speciality. Equally, the increasing use of ovariotomy deeply perturbed him and he spoke out publicly against what he saw as a 'rage for cruel and bloody operations'. ${ }^{105}$ In the case of both procedures, Lee thought the statistics to be unsatisfactory and like Benjamin Phillips believed that many unsuccessful cases were not being disclosed. The contested nature of caesarean section provides an interesting comparison to ovariotomy in this respect, as surgeons and obstetricians were similarly concerned about ascertaining its risks. In 1841, Fleetwood Churchill had produced statistical tables comparing the mortality of various obstetrical operations. Reflecting on his statistics of all caesarean sections known to him to have been performed since 1750, Churchill declared that there had been ' 316 operations, from which 149 mothers recovered and 129 children were saved and 53 lost, in 182 cases where the result was recorded'. ${ }^{106}$ This suggested to Churchill that while the operation was dangerous and should still be considered a last resort, it was less dangerous than previously believed and that the risk was not dissimilar to other more established obstetric procedures like symphyseotomy, 
an operation where the symphysis pubis joint was divided in order to facilitate labour. ${ }^{107}$ Churchill's statistics were swiftly questioned by The Medico-Chirurgical Review, who argued that his collected numbers barely scratched the surface as to the true number of caesarean sections that had been performed in Europe so far, the estimated extent of which led the Review to conclude that 'the real proportionate mortality can...never be accurately ascertained'. ${ }^{108}$ Statistics were being sought as a means of attaining a definitive idea of operative risk, but like ovariotomy statistics, those for caesarean section seemed deeply uncertain. In this way, operative statistics, where data was being retrospectively collected, differed considerably from those for anaesthesia, where statistical methods had been quickly employed soon after it was introduced into practice.

Nonetheless, there were important differences between ovariotomy and caesarean section. The necessity of the latter in extreme circumstances was usually seen as justified. With caesarean section, after all, it was about comparing its risks to other serious operations for obstructed labour. With ovariotomy, the choice was between major surgery and one of the considerably less invasive treatments for ovarian tumours which were still being utilised, such as tapping, application of pressure to the tumour and iodine injections. It was perhaps for this reason that Robert Lee more ardently pursued ovariotomy. He first made his own statistics on the operation public at a meeting of the Royal Medical and Chirurgical Society at the end of the 1850, where he announced that he had collected 108 cases, by which he had calculated a thirty-five per cent mortality rate for all attempted ovariotomies. ${ }^{109}$ The tables, like Phillips', included further cases which had never before been published, mostly constituting single cases which Lee alleged had been communicated privately to him. Two names were noticeably absent though: Daniel Walne and Frederic Bird. Lee claimed that both men had failed to furnish him with the full facts of their experience with ovariotomy and had not published all their unsuccessful cases. Lee's colleague Caesar Hawkins, who since his own failed operation had, like Phillips, become disenchanted with ovariotomy, denounced Bird for holding back details of failed cases while at the same time having 'actually put on record... his opinion of the impropriety of withholding any information from the public with regard to this very operation'. ${ }^{110}$ Bird, who was present at the meeting, expressed shock at the demeaning public denouncement of his work and claimed that he had already sent Lee the statistics for 
his operations thus far: twelve cases, of which eight had been successes. But herein lay the slipperiness in defining what exactly the most desirable method of data collection was. Lee's definition of statistics was quite different from Bird's who believed his notice of twelve cases, without giving any further details, was enough to satisfy Lee in his collection of statistical data. But it was not. For Lee, statistics were not a matter of mere quantification and calculation when it came to operations; statistics, Lee believed, needed to be contextualised with further information about the cases, otherwise they were useless. Thus, the value of numerical data was not a given, even by those who were constructing apparently objective accounts. Rather, they were entirely contingent on narrative as well.

Things went from bad to worse for Bird during the meeting. Pushed into confirming how many attempts he had made to remove an ovarian tumour, whether successful or not, Bird admitted that on numerous other occasions, not reported, he had opened the abdomen to make an exploratory incision. Apparently weary of attempting to diagnose blindly, Bird had begun to open the belly to ensure that ovarian disease was present before he went ahead with an operation. The report of the meeting gives a palpable sense of tension in the crowded room as Bird was asked how many times he had made such an exploratory incision. Bird responded that 'probably he might startle some gentleman by stating as many as forty, or fifty; but of this number he was speaking quite at random'. ${ }^{111}$ Bird denied that any of these exploratory incisions had been fatal, although this was contested by Lee who believed that at least one had been. Regardless, major damage had been done to both Bird's reputation and the cause of ovariotomy. Bird's public humiliation put a well-known face to the vague and nameless fear that dozens, perhaps even hundreds of ovarian procedures were being performed secretly and thus, that the true scale of the operation's mortality was not yet known.

Lee was evidently delighted with the stir his paper had caused and his role in encouraging the profession to think deeply and critically about both ovariotomy and caesarean section, '... in all of which I was victorious, or rather the truth triumphed', he wrote in his diary at the end of the year regarding his public battles. ${ }^{112}$ Lee's use of statistics was ostensibly to attain an objective representation of the operation. But what it had really done was to provide Lee with an opportunity to rather dramatically reveal cases of clandestine abdominal surgery. Indeed, perhaps 
even more important than the statistical calculations he had madethat over a third of those being operated upon had died-was the way in which he had made the withholding of information on ovariotomy now seem completely unacceptable. The operation to remove diseased ovaries had been an ostensibly private endeavour, negotiated between patients, practitioners and eventually, a surgeon willing to undertake the risk of doing the procedure. 'Ovariotomy' was something different; it shifted the operation from a single act to a collective identity, in which all occurrences were expected to be made public. Buttressed by the rapidly expanding medical press, it was now felt the truth of the operation could only be established if it existed publicly and in print. Surgeons who resisted bringing their work into the public sphere were vulnerable to accusations of misconduct. This shift in surgical practice was felt profoundly by those personally and unfortunately involved. Daniel Walne had escaped the full extent of Lee's wrath by sending him more complete information on his cases, but it is telling that by the beginning of the 1850s he had given up performing ovariotomy, as had Samuel Lane. Frederic Bird, who up to now had done more in London than any other practitioner to promote the cause of ovariotomy, at first appeared to escape relatively unscathed from the debacle, responding with a letter to the Lancet again stating his cases, and then publishing a series of articles on the pathology and treatment of ovarian disease in the Medical Times. But in 1852, aged just thirty-four, Bird published his last ovarian case. He retained a respectable post lecturing at Westminster Hospital but was rarely seen in medical society in later life. A telling glance into his world was furnished in an obituary written upon his death in 1874. It noted with a hint of ambiguity that Bird gave up ovariotomy as he was 'averse to the anxieties which are naturally associated with such operations'. ${ }^{113}$ Ironically, in a later publication Lee included Bird's original statistics.

Despite Lee's personal victory, the controversies surrounding Bird only clarified the unsatisfactory nature of surgical statistics. At the same meeting where Bird was accused of concealment, William Lawrence questioned what method was best employed to gather and represent knowledge of the operation. Even though Lee had published as much detail as he could on each case and, where possible, on the length of life afterwards, Lawrence, who was still firmly against the operation, expressed concern as to whether Lee's statistics really got to the bottom of ascertaining the operation's propriety. Lawrence pondered 
how much statistics could tell the profession not only about the extent to which a successful operation prolonged life but also whether that involved a decent quality of life too, a subject I will revisit in Chapter 6. The days, weeks, even months after ovariotomy had been performed were a period of considerable anxiety. Deaths on the operating table or immediately after accounted for around only half of fatal cases and it was, as one Irish surgeon described it, 'the great danger that looms in the distance ${ }^{114}$ — that is the expected onslaught of peritoneal inflammation-that was to be feared as much as the operation itself and which was not easily factored into statistics. Different situations, outcomes and sick bodies made it hard to imagine a typical ovariotomy, and without a sense of what was typical, it was difficult to say which operations should be included in statistics and which should not. Ostensibly, an operation is intrinsically connected to the operator; the two are indivisible: the operation is a product of the surgeon's physical actions. And yet, as Thomas Schlich has shown in his study of twentieth-century surgery, surgeons have often been troubled by how statistics blur the boundaries between the two, especially when outcomes are poor. ${ }^{115}$ Is a fatal outcome caused by the type of operation employed or by an operator's technique? If it is the former, does this exonerate an operator from responsibility? This issue had earlier been highlighted by a Dr. Murphy, who in defending Frederic Bird's practice of the operation at a society meeting published in the Lancet, intriguingly described failed ovariotomies as 'the fault of the operation, not the operator'. ${ }^{116}$ The operation had to be disembodied and made separate from the inherent subjectivities of the surgeon as a means of ascertaining its essential 'truth'.

The ovariotomy debate became a less visible presence in the medical press for several years after Lee's confrontation with Bird; certainly, fewer cases were published. Nonetheless, occasional articles regarding its justifiability cropped up and ovariotomies were still performed with regularity by Charles Clay in Manchester. A new group of Londonbased practitioners also began to take up the operation in the late 1850s, most notably the obstetric physician William Tyler Smith and the surgeons Thomas Spencer Wells and Isaac Baker Brown, the latter of whom had spent years cautioning against the operation, continuing to use only palliative and medical therapeutics to treat dropsical ovaries. ${ }^{117}$ By the end of the 1850 s, however, he had had a change of heart. 
Now convinced that medicine and minor procedures could not effect a permanent cure, he began to advocate using the operation and eventually started performing it himself. ${ }^{118}$ Indeed more generally, there was a significant shift in the operation's standing by the last years of that decade. Many, like Brown, were not entirely confident in the operation but by now, sufficiently unconfident in the various alternatives to do anything to treat the condition. When in 1862 Lee once more publicly derided the lack of truthful representation of ovariotomy's risks, his remarks were met more coolly. ${ }^{119}$ In 1865, a further turning point came with Thomas Spencer Wells' publication of his monograph Diseases of the Ovaries: their Diagnosis and Treatment, which, despite the title, was in fact Wells' record of cases rather than a textbook. In it, Wells provided a verbose, heavily illustrated, richly informative account that he said was of every single ovarian operation he had performed, successes and failures, and where he had carefully divided the operations into completed and uncompleted, and provided noticeably detailed information on the patient's state of health, months and sometimes years after the operation. Through his vivid descriptions of patients who for years had laboured under enormous tumours, some of which were accompanied by evocative images of the suffering woman, Wells made a convincing case for early intervention (see Fig. 3.1). $\mathrm{He}$ also claimed a success rate of seventy-six recoveries for the 114 operations he had performed, results which two years later would be improved upon further by the Edinburgh-based obstetrician Thomas Keith, who in 1867 announced that four-fifths of his ovariotomy patients so far had survived the operation. ${ }^{120}$ Wells' monograph, as will be discussed more thoroughly in the next chapter, was quickly regarded as influential, not least because he carefully seeded the idea among his surgical brethren that he was the surgeon responsible for 'reviving' the fortunes of ovariotomy. Wells' success was less to do with his mortality rate-which at around one-third might still have been considered high by those who depicted ovariotomy as a procedure of choice rather than necessity-but rather the way Wells represented his work. Honest statistics recounting a high number of cases were of the utmost importance. But it was context too that was essential in representing operative surgery, and this could only be provided by full and frank case reports which expressed both the surgeon's narrative and the patient's. 


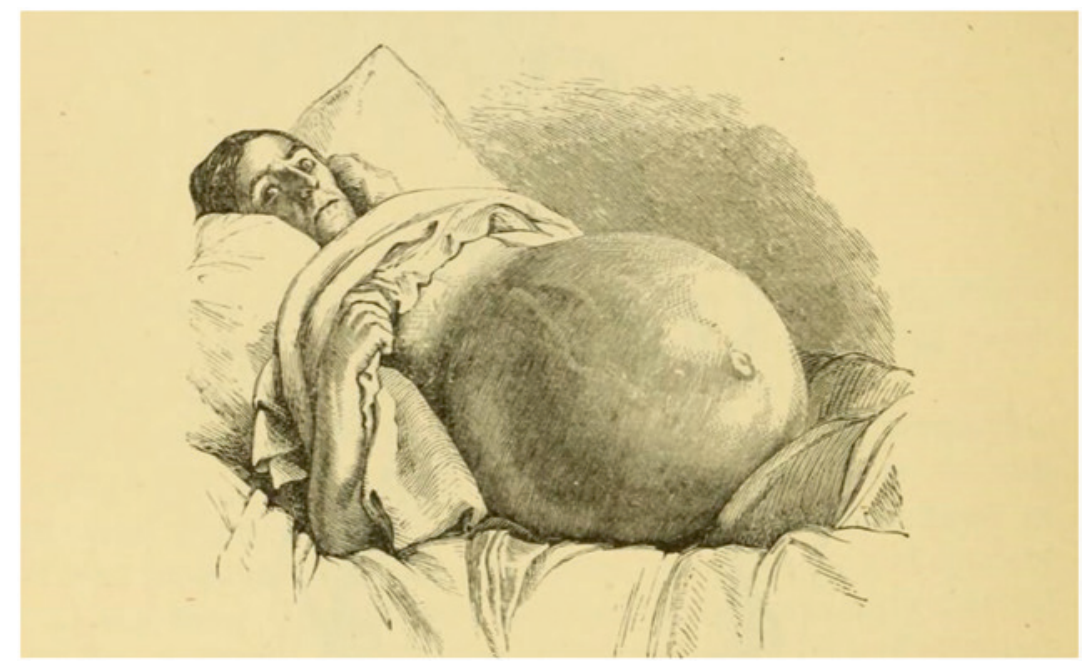

Fig. 3.1 Illustration from Thomas Spencer Wells' Diseases of the Ovaries: their Diagnosis and Treatment (1865) of his patient, 'C.B.', who he had first encountered in 1860. C.B. had suffered from an ovarian tumour for three years before seeking out Wells. The operation was put off for another eighteen months after C.B. was advised by another doctor to try palliative methods instead. When Wells eventually performed the operation, her abdomen was sixty inches in circumference. The patient died soon after. Wells used the case to warn of the risks of delaying ovariotomy (Credit Wellcome Collection/Francis A. Countway Library. CC BY)

\section{CONCLUSION}

During the middle decades of the nineteenth century, the justifiability of removing the ovaries or, as it was known by the 1840s, 'ovariotomy', was hotly debated in Britain by some of the most powerful surgeons in the country. Competing framings of the operation were formed, facilitated by the burgeoning medical press. On the one hand, it was depicted as a sign of advancement by a small but increasingly vocal group of advocates, on the other hand, opponents described it as a dangerous and possibly criminal procedure. Constructing an historical account of an ostensibly 'successful' innovation always runs the risk of characterising detractors along the way as conservative or even backwards looking. As I have 
sought to show here, characterisations of the progressive and, conversely, the regressive in surgery were complicated. Existing as they did in the same professional landscape, the language used by both advocates and opponents of the operation often mirrored one another; sacrifice and salvation, baseness and butchery: evocative terms and concepts such as these were used by the rival camps as they sought to convey an accurate picture of ovariotomy. For both sides, what was crucial was that their representation of the operation could be slotted into rather than contradicting the prevailing ethical framework of surgery. But this was easier said than done. Formulating a collective understanding of ovariotomy's risks and propriety revealed itself to be not only problematic but possibly even unattainable. Establishing the justifiability of the operation proved complicated in the face of the acknowledged messiness of lived experience-operators' differing levels of skill, patients' bodies afflicted with pre-existing illnesses, the role of other actors in the aftercare process- these all needed to be taken into consideration; thus, only through full and frank qualitative accounts of each operation could the 'real' experience of ovariotomy be represented. These accounts, punctured with emotional language and centred upon evocative narratives, allowed operators to express their reasoning for performing the operation, often by utilising the voice of the patient. This was mirrored in the similarly emotive accounts of opponents like Samuel Ashwell and Robert Lee.

This did not negate the desire, however, for clear numerical data. In the 1840s, statistics were increasingly utilised by medical men to help make sense of new and potentially hazardous innovations. They provided control and order, ostensibly permitting a definitive answer as to how risky a treatment or procedure was. The controversies surrounding operators like Frederic Bird made it more important than ever that honest, accurate numbers were provided by all who were performing new and experimental operations. While doctors' criticisms of statistics at this time are recognised by historians, particularly their concern that the individuality of cases would be stripped away, I have sought to show how surgeons negotiated these problems when faced with the urgent need to find an answer to the question of ovariotomy's justifiability. Moreover, I have argued that conceptualisations of the operation as novel and distinct also had an impact on the way its statistics were understood. Only by conveying experiences of ovariotomy through emotive, qualitative accounts and through statistical data, could the advantages and disadvantages of the operation be properly conveyed. 
Throughout the century, the operation would continue to be painted in strikingly different ways: life-saving and life-destroying, progressive and regressive, savage and sophisticated. But it was in these middle decades that the modes used to represent the operation were most intensely scrutinised and deconstructed. The medical community was intent on settling a debate which had serious implications for the practice of surgery and where opponents often feared that the 'truth' of the operation was being obfuscated by secrecy and deception. Even as opinion began to swing in favour of the operation, the ferocity of this past opposition, when those who performed ovariotomy were castigated as 'belly-rippers', was not forgotten. Indeed, its impact would be felt for decades to come.

\section{Notes}

1. John Lizars, Observations on Extraction of Diseased Ovaria (Edinburgh: Daniel Lizars, 1825), 11.

2. 'Observations on Extraction of Diseased Ovaria', The Medico-Chirurgical Review 3 (1825): 344.

3. 'Review: Observations on Extraction of Diseased Ovaria', Lancet 4, no. 103 (17 September 1825): 327.

4. James Blundell, 'On the Surgery of the Abdomen', Lancet 12 (27 June 1829): 355 .

5. Augustus Granville, 'Case in Which an Attempt Was Made to Extirpate Ovarian Tumors', London Medical and Physical Journal 56, no. 330 (1826): 141-143; Alban Smith, 'Account of a Case in Which an Ovarium Was Successfully Extirpated', North American Medical and Surgical Journal 1 (1826): 30-38; Hopfer, 'On Extirpation of Diseased Ovaria' London Medical Gazette 3 (1829): 401-405.

6. Nathan Smith, 'Case of Ovarian Dropsy Successfully Removed by a Surgical Operation', Edinburgh Medical and Surgical Journal 18 (1822): 534.

7. Edward Seymour, Illustrations of Some of the Principal Diseases of the Ovaria (London: Longman, Rees, Orme, Brown and Green, 1830), 89-99; 'Review: "Illustrations of Some of the Principal Diseases of the Ovaria", Edinburgh Medical and Surgical Journal 34 (1830): 139.

8. 'Review: "Illustrations of Some of the Principal Diseases of the Ovaria"', 137.

9. James Blundell, 'Lectures on the Diseases of Women and Children', Lancet 11, no. 290 (21 March 1829): 772.

10. William Jeaffreson, 'A Case of Ovarian Tumour Successfully Removed', Transactions of the Provincial Medical and Surgical Association 5 (1837): 242. 
11. Robert King, 'New Operations for the Removal of Abdominal Tumours', Lancet 27, no. 699 (21 January 1837): 586-590; King had assisted Jeaffreson in his first operation. In 1839, Jeaffreson also reported to the Lancet another successful case by a practitioner in Harleston in the neighbouring county of Norfolk, named Benjamin Crisp. See William Jeaffreson, 'Ovarian Cysts', Lancet 33, no. 846 (16 November 1839): 287.

12. William West, 'Successful Operation for the Removal of an Ovarian Tumour', Lancet 29, no. 743 (25 November 1837): 307-308; John Gorham, 'Observations on the Propriety of Extirpating the Cyst in Some Cases of Ovarian Dropsy', Lancet 33, no. 843 (26 October 1839): 155-161.

13. John Gorham, 'Excision in Ovarian Dropsy', Lancet 33, no. 852 (28 December 1839): 507.

14. 'Physical Society, Guy's Hospital', London Medical Gazette 23 (24 November 1838): 313.

15. One of the most notorious episodes of Liston's rashness involved a small boy admitted under his care at University College Hospital who had a swelling in his neck over the carotid artery. Liston's House-Surgeon Mr. Bucknill had informed Liston that the tumour was pulsating, but Liston found it implausible that a boy so young could have an aneurysm. 'Putting his hand into his right waist-coat pocket, he took out a knife, and made a deep incision into the tumour. Out leaped the arterial blood, and the boy fell upon the floor. The wound was stitched up, and the patient put to bed, the artery being subsequently tied, but without any good result. On examination, it was found that an abscess had existed, and had ulcerated into the carotid'. J.F. Clarke, Autobiographical Recollections of the Medical Profession (London: J. \& A. Churchill, 1874), 391.

16. For more on Liston's surgical style see Reginald Magee, 'Surgery in the Pre-anaesthetic Era: The Life and Work of Robert Liston', Health and History 2, no. 1 (2000): 121-133.

17. Robert Liston, Practical Surgery (London: John Churchill, 1837), v.

18. Robert Liston, Elements of Surgery (London: Longman, 1835), 54.

19. George E. Brickett, 'History of Ovariotomy in Maine', Transactions of the Maine Medical Association 6 (1877): 77.

20. Probably because of their libellous nature, cases where surgeons had been threatened with manslaughter charges were not openly discussed at the time. They are revealed mainly through later retrospective pieces about the history of ovariotomy. In 1895, the British Gynaecological Journal wrote of the Scottish obstetrician Thomas Keith in his obituary that 'it is still credibly believed that if Keith's second case had died he would have been accused of manslaughter by some of his woefully prejudiced critics'. 
Although details are scant about what happened to Keith, other sources appear to corroborate the story that he narrowly escaped legal action for practising ovariotomy. In 1878, Keith himself, for example, described in an article for the British Medical Journal of 'being threatened by an interdict from the Court of Session'. 'Obituary: Thomas Keith', British Gynaecological Journal 11 (1895): 395; Thomas Keith, 'Results of Ovariotomy, Before and After Antiseptics' (1878): 590.

21. Robert King, Jeaffreson's colleague, who himself performed one (successful) extirpation, described ovarian disease as 'a morbid state which has almost invariably been left to exercise its ravages in freedom, the patient falling a sacrifice to it after a series of years of suffering, and of incapacity for useful or pleasurable exertion'. King thus evoked sacrifice too, albeit in a different context to opponents of the operation. King, 'New Operations', 586.

22. Peter Stanley, For Fear of Pain: British Surgery, 1790-1850 (Amsterdam and New York: Rodopi, 2003), 28.

23. More recently Michael Brown has contested the idea that speed was integral to surgery in the early nineteenth century and in fact that 'many surgeons distrusted speed as a marker of skill and saw in the spectre of self-promotion', Michael Brown, 'Redeeming Mr. Sawbone: Compassion and Care in the Cultures of Nineteenth-Century Surgery', Journal of Compassionate Healthcare 4, no. 13 (2017): 5.

24. Lawrence stated that it was 'the boast of modern surgery to have greatly diminished the number of operations'. William Lawrence, 'Lectures on Surgery, Medical and Operative. Lecture 1: Introduction', Lancet 13, no. 318 (3 October 1829): 38. See also Stephen Jacyna, Philosophic Whigs: Medicine, Science and Citizenship in Edinburgh, 1789-1848 (London: Routledge, 1994), 115-124.

25. Adrian Desmond, The Politics of Evolution: Morphology, Medicine and Reform in Radical London (Chicago: University of Chicago Press, 1989), 101-110.

26. Ornella Moscucci, The Science of Woman: Gynaecology and Gender in England 1800-1929 (Cambridge University Press, 1990), 141.

27. 'Extirpation of Ovarian Tumors', London Medical and Physical Journal 59 (1828): 175. The journal editor was Roderick MacLeod, a renowned conservative and rival of Thomas Wakley.

28. Keir Waddington, Medical Education at St. Bartholomew's Hospital, 1123-1995 (Woodbridge: Boydell Press, 2003), 60.

29. Lawrence, 'Lectures on Surgery, Medical and Operative. Lecture 1', 36.

30. William Lawrence, 'Lectures on Surgery, Medical and Operative. Lecture 2: On the Nature and Seat of Diseases', Lancet 13, no. 319 (10 October 1829): 65 . 
31. William Lawrence, 'Lectures on Surgery: Lecture LXXV', London Medical Gazette 6 (21 August 1830): 822-828, 827.

32. Robert Liston, 'Practical Surgery: A Course of Lectures on the Operations of Surgery and Diseases and Accidents Requiring Operations', Lancet 45, no. 1119 (8 February 1845): 147. The couplet was taken from part two of Butler's English Civil War parody Hudibras (1664).

33. Helen Macdonald, Possessing the Dead: The Artful Science of Anatomy (Carlton: Melbourne University Press, 2010), 15.

34. For a detailed history of the body-snatching scandals and their societal impact, see Ruth Richardson, Death, Dissection and the Destitute: The Politics of the Corpse in Pre-Victorian Britain (London: Routledge, 1987).

35. King, 'New Operations', 587.

36. This characterisation of surgeons was most famously embodied in Charles Dickens' depiction of the bloodthirsty surgical students Bob Sawyer and Benjamin Allen in his 1837 novel The Pickwick Papers, in which the two young men enthusiastically relate to Mr. Pickwick the bloody operations they are witness to. Charles Dickens, The Pickwick Papers (London: Penguin, 1994), 483.

37. 'Extirpation of Ovarian Tumors', 175.

38. Charles Clay, The Results of All Operations for the Extirpation of Diseased Ovaria (Manchester: W.M. Irwin, 1848), 56.

39. Charles Clay, 'Ovariotomy', Medical Times 9, no. 211 (7 October 1843): $4-5$.

40. 'Extirpation of Ovaria', Lancet 43, no. 1074 (30 March 1844): 45-47.

41. Mary Fissell, 'The Disappearance of the Patient's Narrative and the Invention of Hospital Medicine', in British Medicine in an Age of Reform, ed. Roger French and Andrew Wear (Abingdon: Routledge, 1991): 93.

42. Brian Hurwitz, 'Form and Representation in Clinical Reports', Literature and Medicine 25, no. 2 (2006): 229.

43. Meegan Kennedy, Revising the Clinic: Vision and Representation in Victorian Medical Narrative and the Novel (Columbus: Ohio State University Press, 2010), 23. It also speaks to work by Sarah Chaney on the history of madness. Chaney argues that, contrary to the general picture of Victorian approaches to madness as authoritarian, late nineteenth-century alienists put high value upon individual case histories and patient experience. See Sarah Chaney, "“A Hideous Torture on Himself": Madness and Self-Mutilation in Victorian Literature', Journal of Medical Humanities 32, no. 4 (2011): 281. 
44. Claire Brock, 'Risk, Responsibility and Surgery in the 1890s and Early 1900s', Medical History 57, no. 3 (2013): 319-326.

45. Regina Morantz-Sanchez, Conduct Unbecoming of a Woman: Medicine on Trial in Turn-of-the-Century Brooklyn (Oxford: Oxford University Press, 1999), 106-107.

46. Regina Morantz-Sanchez, 'Negotiating Power at the Bedside: Historical Perspectives on Nineteenth-Century Patients and Their Gynecologists', Feminist Studies 26, no. 2 (2000): 287-309.

47. Stanley, For Fear of Pain, 198-199.

48. Benjamin Phillips, 'Extraction of an Ovarian Cyst', London Medical Gazette 27 (9 October 1840): 83.

49. Phillips, 'Extraction of an Ovarian Cyst', 83.

50. Phillips, 'Extraction of an Ovarian Cyst', 84.

51. Phillips, 'Extraction of an Ovarian Cyst', 85.

52. Phillips, 'Extraction of an Ovarian Cyst', 86.

53. Phillips, 'Extraction of an Ovarian Cyst', 87.

54. Charles Clay, 'Cases of Peritoneal Section', Medical Times 7 (26 November 1842): 141.

55. Clay, 'Cases of Peritoneal Section' (26 November 1842): 141.

56. Charles Clay, 'Cases of Peritoneal Section', Medical Times 7 (15 October 1842): 44.

57. Clay, 'Cases of Peritoneal Section' (26 November 1842): 140.

58. Phillips, 'Extraction of an Ovarian Cyst', 84.

59. Daniel H. Walne, Cases of Dropsical Ovaria Removed by the Large Abdominal Section (London: Longman, Brown, Green, and Longmans, 1843), 42. The pamphlet brought together three cases Walne had published in the London Medical Gazette between 1842 and 1843.

60. Joyce L. Huff has argued that within mid-nineteenth-century culture fatness potentially represented a destabilising 'otherness' to the ordered body, defying an exacting Victorian aesthetic which 'was a matter not so much of maintaining a thin body as of maintaining a "properly" shaped body'. Joyce L. Huff, 'A “Horror of Corpulence”: Interrogating Bantingism and Mid-Nineteenth-Century Fat-Phobia', in Bodies out of Bounds: Fatness and Transgression, ed. Jana Evans Braziel and Kathleen LeBesco (Berkeley: University of California Press, 2001), 44.

61. Walne, Cases of Dropsical Ovaria, 8.

62. Numerous cases recorded women's anxieties over their inability to work due to their condition. See King, 'New Operations', 589; Walne, Cases of Dropsical Ovaria, 42. Marjorie Levine-Clarke has emphasised (albeit in a broader context than surgery) that within lower socio-economic classes, women conceptualised their own health and negotiated their health care in the context of their employability. 
Marjorie Levine-Clarke, Beyond the Reproductive Body: The Politics of Women's Health in Early Victorian England (Columbus: Ohio State University Press, 2004), 1-11.

63. Samuel Ashwell, 'Extirpation in Ovarian Dropsy', The Boston and Medical and Surgical Journal 45 (4 June 1845): 357.

64. Ashwell, 'Extirpation in Ovarian Dropsy', 358.

65. Frederic Bird, 'Diagnosis, Pathology and Treatment of Ovarian Tumours', Medical Times 24, no. 57 (2 August 1851): 123.

66. Bird, 'Diagnosis, Pathology and Treatment', 123.

67. Bird, 'Diagnosis, Pathology and Treatment', 123.

68. Flurin Condrau, 'The Patient's View Meets the Clinical Gaze', Social History of Medicine 20, no. 3 (2007): 529.

69. Brown, 'Redeeming Mr. Sawbone', 3.

70. Stanley, For Fear of Pain, 233.

71. Brown, 'Redeeming Mr. Sawbone', 5.

72. James Young Simpson, 'Lecture Notes or Model Answers for Exams in Obstetrics and Gynaecology with a Section Discussing Ovariotomy', (c. 1848-1850) JYS/326 (Royal College of Surgeons of Edinburgh).

73. 'Ovarian Dropsy', Medical Times 10 (1 April 1844): 11.

74. 'Results of the Operation for the Extirpation of Diseased Ovaria: Review', London Medical Gazette 44 (23 November 1849): 899.

75. 'Extirpation of Ovarian Tumors', The Medico-Chirurgical Review 40 (1 April 1844): 557.

76. The example of surgery for squinting was not an indiscriminate choice on the part of The Medico-Chirurgical Review. In the early 1840s, a new operation for curing squinting by sectioning the media rectus muscle had been developed by Berlin surgeon Johann Dieffenbach and the operation had very rapidly spread across Europe.

77. Fleetwood Churchill, 'Ovariotomy', The Medico-Chirurgical Review 42 (1 October 1844): 528.

78. Churchill, 'Ovariotomy', 528.

79. Statistics played an integral part in eighteenth-century medicine. Tröhler cites the use of statistics, for example, to measure mortality in lithotomy and amputations. Ulrich Tröhler, Quantification in British Medicine and Surgery 1750-1830, With Special Reference to its Introduction into Therapeutics (PhD thesis, University College London, 1978); Ulrich Tröhler, 'Quantifying Experience and Beating Biases: A New Culture in Eighteenth-Century British Clinical Medicine', in Body Counts: Medical Quantification in Historical and Sociological Perspective, ed. Gérard Jorland, Annick Opinel, and George Weisz (Montreal: McGill-Queens University Press, 2005), 19-50. 
80. Ian Hacking, The Taming of Chance (Cambridge: Cambridge University Press, 1990), 2.

81. For a useful overview on both the history and historiography of medical statistics, see Gérard Jorland and George Weisz, 'Introduction: Who Counts?', in Body Counts: Medical Quantification in Historical and Sociological Perspectives, ed. Gérard Jorland, Annick Opinel, and George Weisz (Montreal: McGill-Queens University Press, 2005), 3-15.

82. Thomas Schlich and Ulrich Tröhler, 'Risk and Medical Innovation: A Historical Perspective', in The Risks of Medical Innovation, ed. Thomas Schlich and Ulrich Tröhler (Abingdon: Routledge, 2006), 5-7.

83. For a background to this argument, see Patricia Jasen, 'Breast Cancer and the Language of Risk, 1750-1950', Social History of Medicine 15, no. 1 (2002): 17-43.

84. The Google Ngram Viewer (http://books.google.com/ngrams) allows one to track the use of a particular word in the 5.2 million books digitised by Google. The Ngram for 'risk' shows infrequent but growing use of the word in the nineteenth century. But a quick search of the Lancet during the early nineteenth century brings up a plethora of articles where operative 'risk' is described by influential surgeons. See, for example, William Lawrence, 'A Lecture Introductory to a Course of Surgery', Lancet 11, no. 285 (14 February 1829): 617. Lawrence warned his students: 'in any operation you have to perform, unless the knife is guided by anatomical knowledge, consider the risk of the patient, and that of yourself, as the operator', 617.

85. Jasen, 'Breast Cancer', 18.

86. Martin Pernick, The Calculus of Suffering: Pain, Professionalism, and Anesthesia in Nineteenth Century America (New York: Columbia University Press, 1985), 213.

87. Pernick characterises the operation in the 1840 s as one where the ovaries were being removed to rectify nervous illnesses, which, as will be explored in the following two chapters, was a development that in fact came much later. Pernick, The Calculus of Suffering, 213.

88. Most practitioners performing ovariotomy described using chloroform in their cases soon after it was introduced. Charles Clay also wrote in private to James Young Simpson to declare himself 'converted' to chloroform. However, by 1863 Clay had begun to cast doubt on the helpfulness of chloroform in abdominal surgery, stating that if an ovariotomy patient could face the operation without it, then it would be in her favour not to have it. Letter to James Young Simpson from Charles Clay (n.d.) JYS/200 (Royal College of Surgeons of Edinburgh); 'Obstetrical Society of London', Medical Times and Gazette 1 (4 March 1863): 407-408. 
89. Ian Burney, 'Anaesthetic and the Evaluation of Surgical Risk in MidNineteenth-Century Britain', in The Risks of Medical Innovation, ed. Thomas Schlich and Ulrich Tröhler (Abingdon: Routledge, 2006), 38.

90. These concerns were evidently well known beyond the medical community. In 1847 , the satirical magazine Punch published a poem entitled 'The Blessings of Chloroform' with the couplet 'Chloroform will render quite agreeable the parting with/any useless member that a patient has been smarting with'. Fears about chloroform's power to extend the realm of surgery meant that surgeons' performance of new and risky operations was more closely scrutinised than ever before. 'The Blessings of Chloroform', Punch 13 (18 December 1847): 232.

91. Burney, 'Anaesthetic and the Evaluation of Surgical Risk', 40.

92. Charles Clay, Cases of Peritoneal Section (London: Munro and Congreve, 1842). The pamphlet brought together the five cases he had published in the Medical Times.

93. Clay, 'Cases of Peritoneal Section', 18.

94. 'Review: "Cases of Peritoneal Section"', British and Foreign Medical Review 16 (1843): 394.

95. Benjamin Phillips, 'Observations on the Recorded Cases of Operations for the Extraction of Ovarian Tumours' Medico-Chirurgical Transactions 27 (1844): 468-492; Churchill, 'Ovariotomy', 528-531.

96. Benjamin Phillips, 'Observations on the Recorded Cases of Operations for the Extraction of Ovarian Tumours', Medico-Chirurgical Transactions 27 (1844): 469.

97. Phillips, 'Observations on the Recorded Cases', 475.

98. Churchill, 'Ovariotomy', 530.

99. Broadly speaking, 'capital' operations usually referred to lithotomy and lithotrity, major amputations such as at the shoulder or the thigh, operations for strangulated hernias and the ligaturing of major arteries-any operation where there was believed to be a relatively high risk of death. However, what exactly constituted a 'high' risk was never well defined.

100. This was the subject of a lecture on ovariotomy by St. Thomas' Hospital surgeon Samuel Solly in 1846. Solly, an advocate of the operation, collated numerous statistics to suggest that the mortality rate for ovariotomy was about four in ten. He compared this to the numbers for other capital operations such as amputation of the thigh, where there was a mortality rate of about three and a half out of ten, amputation of the arm (four out of ten), and Sir Astley Cooper's hernia operations, where nearly five in every ten patients had died. Samuel Solly, 'Clinical Lecture on Ovariotomy', London Medical Gazette 38 (3 July 1846): 54.

101. Clay, 'Cases of Peritoneal Section', 16. 
102. James Young Simpson often used this argument. It formed part of a long discussion about the operation which he participated in at the MedicoChirurgical Society of Edinburgh on 17 December 1845: 'MedicoChirurgical Society of Edinburgh', The Monthly Journal of Medical Science 6, no. 4 (1846): 56-59.

103. James Matthews Duncan, 'Is Ovariotomy Justifiable?', Lancet 69, no. 1748 (28 February 1857): 212-214. Duncan described ovariotomy as having a 'distinct, individual character' and thus was incomparable to other operations, 213.

104. See for instance 'Biographical Sketch of Robert Lee; M.D., F.R.S.', Lancet 57, no. 1438 (22 March 1851): 332-337. Biographical sketches of this magnitude appeared only occasionally in the Lancet during the 1850s, attesting to the authority Lee wielded in the London medical world.

105. 'Royal Medical and Chirurgical Society', Lancet 57, no. 1432 (8 February 1851): 155.

106. Fleetwood Churchill, Researches on Operative Midwifery (Dublin: Martin Kenne and Son, 1841), 222.

107. Churchill estimated that about half of babies were lost when symphyseotomy was performed, compared to over two thirds when caesarean section was undertaken. He used both statistics and contextual information to claim that although more mothers survived symphyseotomy than caesarean section, many were badly injured by the former procedure, leading Churchill to declare that their risks were roughly the same. Churchill, Researches on Operative Midwifery, 254.

108. 'Review: "A Practical Treatise on Midwifery" by M. Chailly', The Medico-Chirurgical Review 41 (1 October 1844): 407.

109. 'Royal Medical and Chirurgical Society, November 13th 1850', Lancet 56, no. 1421 (23 November 1850): 584.

110. 'Royal Medical and Chirurgical Society', 584.

111. 'Royal Medical and Chirurgical Society', 585-586.

112. Diary of Robert Lee, Vol. 6 (1838-1872), MS3218 (Wellcome Collection).

113. 'Obituary: Frederic Bird', Medical Times and Gazette 1 (9 May 1874): 520.

114. Richard G. Butcher, 'On Ovariotomy, and the After-Treatment of the Patient', Dublin Quarterly Journal of Medical Science 40, no. 2 (1865): 283.

115. Thomas Schlich, Surgery, Science and Industry: A Revolution in Fracture Care, 1950s-1990s (Basingstoke: Palgrave Macmillan, 2002), 122-123.

116. 'Westminster Medical Society', Lancet 50, no. 1261 (30 October 1847): 467. Four years before, the surgeon John Halton similarly highlighted the distinction between surgeon and operation, suggesting that statistics 
for capital operations should eschew altogether those failed cases where the performance of the operator rather than the operation itself was deemed at fault. John Halton 'On the Average Number of Deaths in Capital Operations’, London Medical Gazette 33 (29 December 1843): 390-400.

117. Brown had also advocated a method that involved wrapping the abdomen in tight bandages so as to put pressure upon the abdomen and thus reduce swelling. Isaac Baker Brown, 'Practical Remarks on the Cure of Ovarian Dropsy Without Abdominal Section', Lancet 43, no. 1083 (1 June 1844): 306-307.

118. Isaac Baker Brown, On Some Diseases of Women Admitting of Surgical Treatment (London: John Churchill, 1854). In this publication, Brown detailed all his cases of ovariotomy so far.

119. 'Royal Medical and Chirurgical Society, Tuesday November 11th, 1862', Lancet 80, no. 2047 (22 November 1862): 565-569.

120. Thomas Spencer Wells, Diseases of the Ovaries: their Diagnosis and Treatment, vol. 1 (London: John Churchill, 1865), xiii; Thomas Keith, 'Fifty-One Cases of Ovariotomy', Lancet 90, no. 2297 (7 September 1867): 290-291.

Open Access This chapter is licensed under the terms of the Creative Commons Attribution 4.0 International License (http://creativecommons.org/licenses/ by $/ 4.0 /$ ), which permits use, sharing, adaptation, distribution and reproduction in any medium or format, as long as you give appropriate credit to the original author(s) and the source, provide a link to the Creative Commons license and indicate if changes were made.

The images or other third party material in this chapter are included in the chapter's Creative Commons license, unless indicated otherwise in a credit line to the material. If material is not included in the chapter's Creative Commons license and your intended use is not permitted by statutory regulation or exceeds the permitted use, you will need to obtain permission directly from the copyright holder.

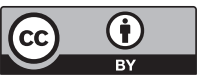

